\title{
Microstructure and Mechanical Properties of Ti-5Al-2.5Fe Alloy Produced by Powder Forging
}

\author{
Mingtu Jia ${ }^{1, a^{*}}$, Clément Blanchard ${ }^{2, b}$, Leandro Bolzoni ${ }^{1, c}$ \\ ${ }^{1}$ Waikato Centre for Advanced Materials, School of Engineering, The University of Waikato, \\ Private Bag 3105, 3240 Hamilton - New Zealand \\ ²Ei.CESI, Engineering School, Boulevard de I'Université, 44600 Saint-Nazaire, France \\ amingtujia@gmail.com, bclement.blanchard447@gmail.com, cleandro@waikato.ac.nz
}

Keywords: Blending elemental, powder forging, Ti-5Al-2Fe alloy, heat treatment

\begin{abstract}
Blended elemental powder metallurgy is a cost effective approach to produce near net shape titanium alloy parts; however, the residual pores remaining in sintered parts are detrimental to the mechanical properties. In this study, elemental powders ( $\mathrm{Ti}, \mathrm{Al}$ and $\mathrm{Fe}$ ) were used to produce the Ti-5Al-2Fe alloy by a powder forging process, involving cold compaction, vacuum sintering, forging and heat treatment. The residual pores of the sintered parts were removed completely by forging at the temperature of $1250^{\circ} \mathrm{C}$. The effect of solution and aging and mill annealing heat treatments on the mechanical properties of the forged Ti-5Al-2Fe parts were studied. It is found that the ductility of the forged Ti-5Al-2Fe parts is improved significantly by both solution and aging treatment and mill annealing, without decreasing their ultimate tensile strength, which sits around $1000 \mathrm{MPa}$. The enhancement of the mechanical behaviour is justified via understanding the evolution of the residual porosity and of the microstructural features of the materials.
\end{abstract}

\section{Introduction}

Titanium and titanium alloys have been drawn more attention on manufacturing a variety of components in aerospace [1], automobile [2], marine [3], chemical [3] and biomedical [4] industries. Especially they are highly demanded to manufacture prosthesis and implants for the medical and dental fields [5, 6], due to their low Young's modulus, good corrosion resistance and excellent biocompability. As the titanium alloy workhorse, Ti-6Al-4V (wt\%) has been widely used to produce various prosthesis as an implant material [6]. Recently, V-free titanium alloys such as Ti-6Al-7Nb (wt\%) [7-9] and Ti-5Al-2.5Fe (wt\%) [10, 11] have been developed to replace Ti-6Al-4V alloy in the medical application, to avoid the toxicity caused by element V. Among these, the addition of Fe is regarded as an effective way to reduce the cost of titanium alloys by replacing expensive alloying elements (e.g. V, Nb, Mo and Zr) [2, 12]. Similarly, powder metallurgy is gaining momentum as effective near net shape methods to produce titanium-based components because they are considered low cost manufacturing process $[13,14]$. In powder metallurgy, the blended elemental approach is a cost effective to produce titanium and its alloy components using elemental powders $[15,16]$. The aim of this work is to study the feasibility of using the blended elemental powder metallurgy route to produce titanium alloys parts, specifically considering the $\alpha+\beta$ Ti-5Al-2.5Fe alloy, by means of the conventional powder forging process seeking to synthesize fully dense Ti-5Al-2.5Fe components. Solution plus aging and mill annealing heat treatments are also investigated aiming to understand their effect on the microstructural features and mechanical properties of the as-forged Ti-5Al-2.5Fe parts.

\section{Experimental Procedure}

Hydride-dehydride (HDH) Ti powder, pure atomized Al powder and Carbonyl Fe powder were used to synthesize the Ti-5Al-2.5Fe alloy in this study. The powders, whose characteristics are listed in Table 1, were mixed for 24 hours using a two-roll mill. 
Table 1. Characteristics of the powders used in this studied.

\begin{tabular}{cccc}
\hline Powder & Particle size & Particle shape & Purity \\
\hline $\mathrm{Ti}$ & $<75 \mu \mathrm{m}$ & irregular & $>99.5 \%$ \\
$\mathrm{Fe}$ & $5-9 \mu \mathrm{m}$ & irregular & $>99.0 \%$ \\
$\mathrm{Al}$ & $45-75 \mu \mathrm{m}$ & spherical & $>99.7 \%$ \\
\hline
\end{tabular}

After blending, the powder mixtures were uniaxially pressed into a cylindrical compact at $400 \mathrm{MPa}$ at room temperature. Then, the compacts were sintered under vacuum at the temperature and soaking time of $1250^{\circ} \mathrm{C}$ and 2 hours. Subsequently, the sintered parts were forged into a disc at the temperature of $1250^{\circ} \mathrm{C}$ in air. For the solution and aging treated, the as-forged material was solution treated at the temperature of $950^{\circ} \mathrm{C}$ for 2 hours, quenched in water, and finally aged at the temperature of $550^{\circ} \mathrm{C}$ for 8 hours. On the other hand, another as-forged material was mill annealed by the combination of $750^{\circ} \mathrm{C}$ as temperature and 10 hours of treatment time.

$\mathrm{X}$-ray diffraction (XRD) using $\mathrm{Cu} \mathrm{K}_{\alpha}$ radiation source at a scanning rate of $2 \% \mathrm{~min}$ was carried out to determine the phase constituents of forged Ti-5Al-2.5Fe alloy. The metallographic sample were ground, polished and etched by Kroll's reagent (2 ml HF, $6 \mathrm{ml} \mathrm{HNO}$ and $92 \mathrm{ml}$ distilled water) to reveal their microstructure which was examined via optical microscopy (Olympus BX60) and scanning electrical microscopy (SEM, Hitachi S4700). Flat dog-bone specimens with a cross section of $2 \times 2 \mathrm{~mm}^{2}$ for tensile test were prepared from each manufacturing process including vacuum sintering, forging, solution and aging treatment and mill annealing treatment. The tensile test was done at room temperature at a strain rate of $1 \times 10^{-4} \mathrm{~s}^{-1}$. During the testing, the strain was recorded by an extensometer. The fracture surface of the tensile specimens was also examined using SEM.

\section{Results and Discussion}

Figure 1a) shows that the microstructure of vacuum sintered Ti-5Al-2.5Fe alloy is a fully lamellar structure consisting of coarse $\alpha$ lamellae and fine $\beta$ lath between the $\alpha$ lamellae. It can be noticed that a homogeneous microstructure has been synthesized by vacuum sintering at $1250^{\circ} \mathrm{C}$ for 2 hours. However, a large amount of pores are still present in the sintered part and they are detrimental for the mechanical properties, as pores will act as crack initiation sites once the materials is loaded.
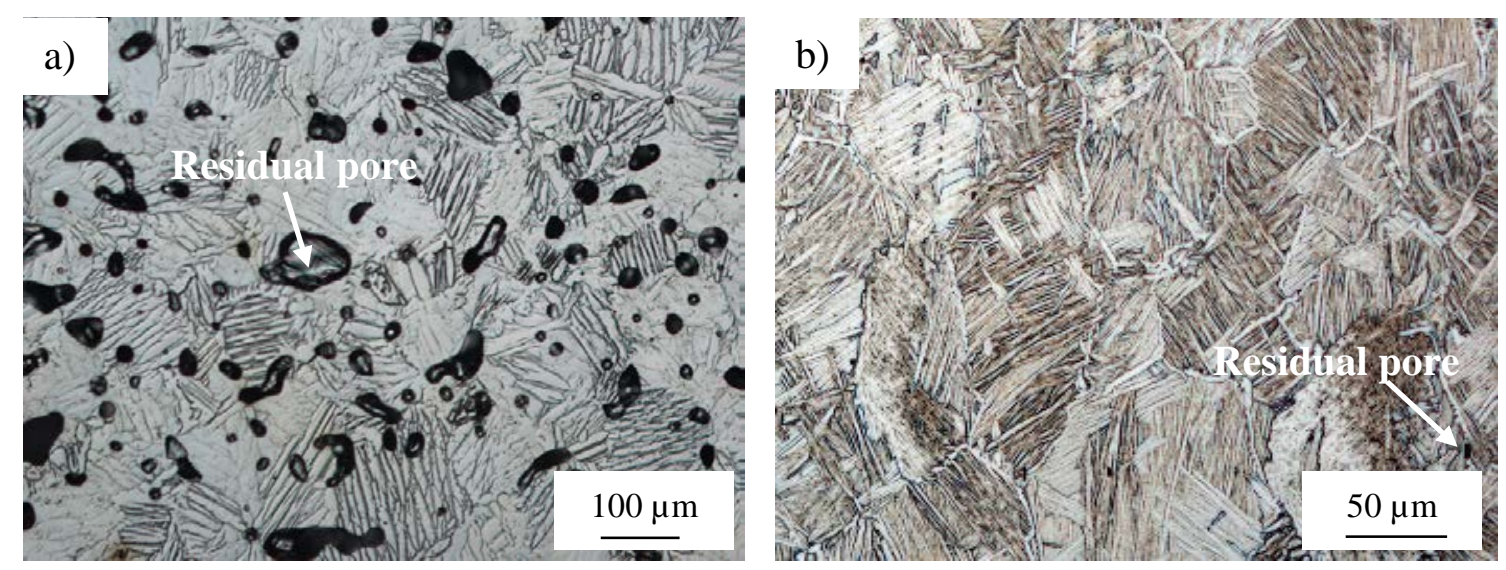

Figure 1. Optical micrographs of (a) the vacuum sintered and (b) the as-forged Ti-5Al-2.5Fe alloy.

To remove the residual porosity, forging was performed to collapse the pores by plastic deformation. Pores are actually nearly completely removed after forging with the exception of a small amount of elongated pores still present (Figure 1b). The microstructure of as-forged part is also a fully lamellar structure; however, the width of $\alpha$ lamellae in the as-forged part is much finer than those found in the vacuum sintered part and this is attributed to the faster cooling rate of the former process. Specifically, forged parts are naturally cooled in air while sintered parts are furnace cooled. The XRD pattern in Figure 2 shows that the as-forged Ti-5Al-2.5Fe alloy has $\alpha$ phase and a small amount of transformed $\beta$ phase, which is in agreement with the results of the microstructural analysis. 


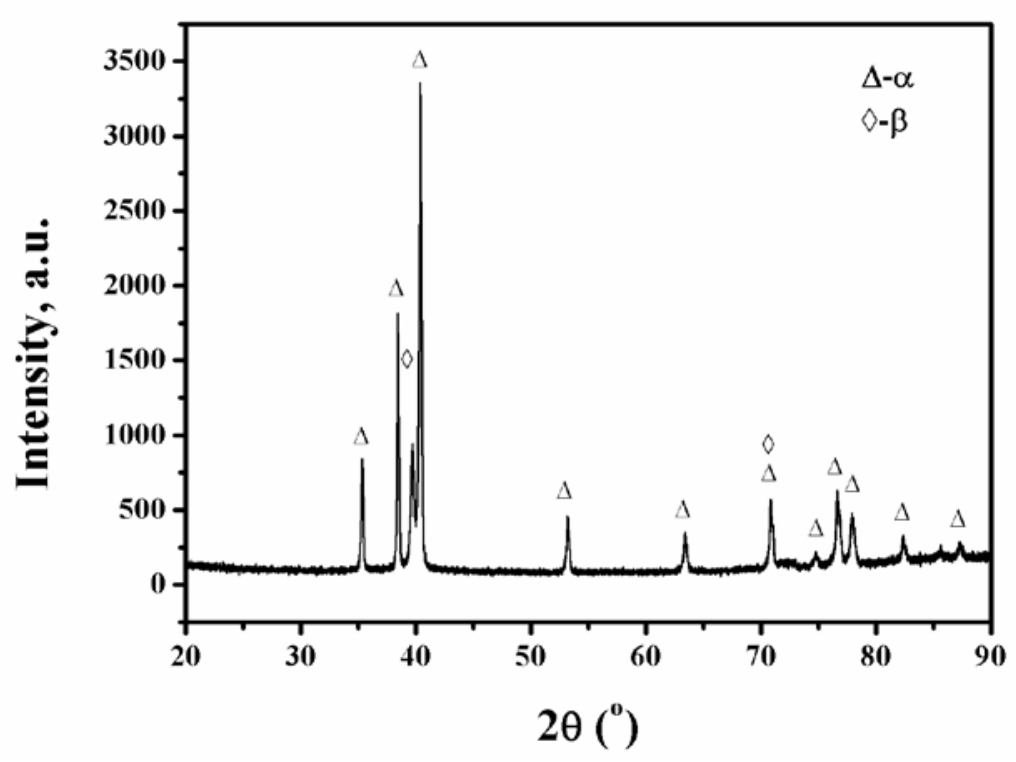

Figure 2. XRD pattern of the as-forged Ti-5Al-2.5Fe alloy.

Subjected to solution and aging treatment, the microstructure of the forged alloy transformed into a coarse fully lamellar structure with a smaller $\alpha$ length/width aspect ratio of 11 as per image analysis (Figure 3a). Moreover, the shape of residual porosity turned into rounded pores, which is consistent with the pore rounding during the sintering process. Performing a mill annealing at the temperature of $750^{\circ} \mathrm{C}$ for 10 hours keeps the microstructure of the forged part as a fine fully lamellar structure with the absence of severe microstructure coarsening (Figure 3b). Furthermore, the shape of residual pores becomes spherical after mill annealing.
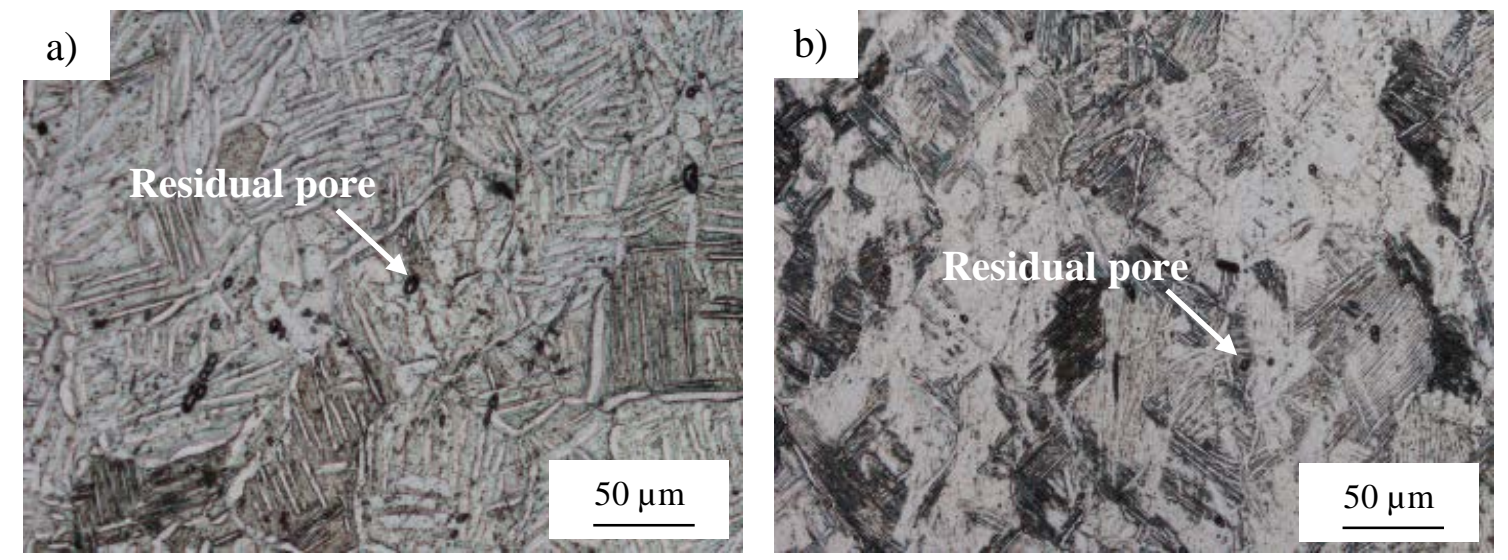

Figure 3. Optical micrographs of (a) the solution plus aging treated and (b) the mill annealed Ti-5Al-2.5Fe alloy.

Typical tensile engineering stress-strain curves of the sintered, forged and heat treated Ti-5Al-2.5Fe alloy are shown in Figure 4. The vacuum sintered part has a yield strength (YS) of $710 \mathrm{MPa}$, a fracture strength of $812 \mathrm{MPa}$ and an elongation to fracture of $0.7 \%$. Its low elongation to fracture is caused by the large amount of residual pores left by the sintering, which makes the material to fracture in a fairly brittle way. After forging, YS, ultimate tensile strength (UTS) and elongation to fracture of the as-forged part are increased to $947 \mathrm{MPa}, 1020 \mathrm{MPa}$ and $4.2 \%$, respectively, as a result of the removal of residual pores by forging. However, the residual elongated pores still has still a critical effect on the elongation to fracture of the as-forged alloy due to the stress concentration at the sharp edge of elongated pores. Heat treatment can help in smoothing the sharp edge of residual pores left by forging via pore rounding. 


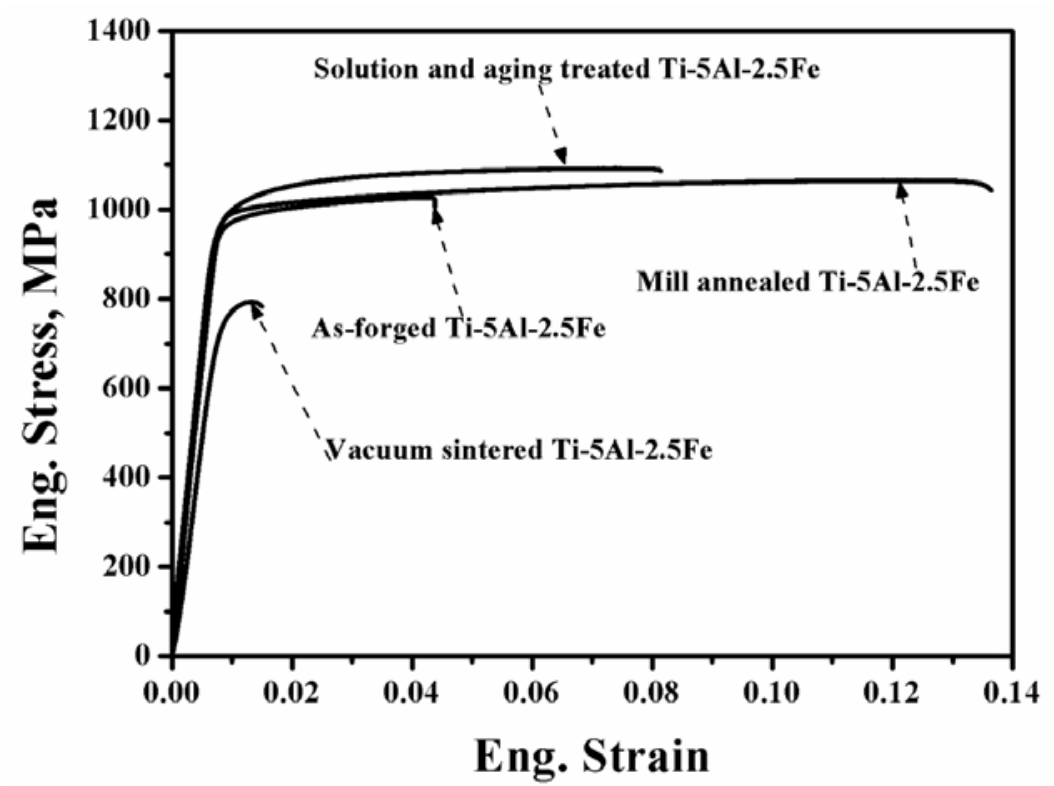

Figure 4. Engineering stress-strain curves of sintered, forged and heat treated Ti-5Al-2.5Fe alloy.

Consequently, after the solution and aging treatment the elongation to fracture of heat treated part was improved to be $6.6 \%$ meanwhile the yield strength and UTS were significantly increased to be $997 \mathrm{MPa}$ and $1096 \mathrm{MPa}$, respectively. The increase of the tensile strength is attributed to the reduction of $\alpha+\beta$ colony size, which is the main parameter to determine the strength of two phase titanium alloy [17]. Via the mill annealing treatment the elongation to fracture is increased to $11.0 \%$ while achieving YS and UTS of $996 \mathrm{MPa}$ and $1068 \mathrm{MPa}$, respectively. The improvement of the mechanical properties of the forged materials is the consequence of the switch of the morphology of the residual pores. Additionally, the change of phase fraction after heat treatments could also affect the mechanical properties of the forged materials, further study is needed to clarify this aspect. Although there are a few residual pores present in the forged Ti-5Al-2.5Fe part which are not removed by the subsequent heat treatment, the mechanical properties of forged and heat treated Ti-5Al-2.5Fe alloys are comparable to those of cast Ti-5Al-2.5Fe [18] and wrought Ti-6Al-4V (Table 2) [19]. Therefore, the low cost Ti-5Al-2.5Fe parts produced by powder forging in this study could be a good alternative to replace the Ti-6Al-4V alloy in different engineering applications.

Table 2. Tensile properties of powder forged Ti-5Al-2.5Fe, cast Ti-5Al-2.5Fe and wrought Ti-6Al-4V alloy.

\begin{tabular}{ccccc}
\hline Material & $\begin{array}{c}\text { YS } \\
\text { (MPa) }\end{array}$ & $\begin{array}{c}\text { UTS } \\
\text { (Mpa) }\end{array}$ & $\begin{array}{c}\text { Elongation } \\
\text { to fracture }\end{array}$ & Ref. \\
\hline Forged Ti-5Al-2.5Fe & $947 \pm 13$ & $1020 \pm 7$ & $4.2 \% \pm 0.7$ & This study \\
Solution and aged Ti-5Al-2.5Fe & $997 \pm 12$ & $1096 \pm 7$ & $6.6 \% \pm 1.0$ & This study \\
Mill annealed Ti-5Al-2.5Fe & $996 \pm 5$ & $1068 \pm 3$ & $11 \% \pm 1.6$ & This study \\
Casted Ti-5Al-2.5Fe & 820 & 900 & 6 & {$[18]$} \\
Annealed wrought Ti-6Al-4V & 875 & 965 & $13 \%$ & {$[19]$} \\
Solution and aged Ti-6Al-4V & 1151 & 1103 & $13 \%$ & {$[19]$} \\
Mill annealed Ti-6Al-4V & 945 & 1069 & $10 \%$ & {$[19]$} \\
\hline
\end{tabular}

Figure 5 shows the fracture morphologies of the vacuum sintered, as-forged and heat treated Ti-5Al-2.5Fe alloy. The vacuum sintered Ti-5Al-2.5Fe part has a dimples fracture pattern with a large amount of residual pores in the fracture surface. The forged Ti-5Al-2.5Fe part has both dimples and cleavage fracture pattern with a few residual pores in the fracture surface. In the case of the solution and aging treated, the material has a fracture surface showing both dimples and cleavage feature, which is consistent with its better ductility and higher strength with respect to the forged part. The 
fracture surface of the mill annealed alloy consists of a large amount of dimples (Figure 5d), which is in agreement with its higher ductility compared to the other processing conditions. As a result, the heat treatment in this study enables the fracture mode of the forged part to transform from brittle (i.e. cleavage) to ductile (i.e. dimples).


Figure 5. Fracture morphology of the Ti-5Al-2.5Fe alloy: a) vacuum sintered, b) forged, c) solution and aged, and d) mill annealed.

\section{Conclusions}

Conventional powder forging including vacuum sintering and forging was used to produce fully dense Ti-5Al-2.5Fe parts. A large amount of residual pores were removed by the forging process, except a small amount of elongated residual pores. Due to the stress concentration of elongated residual pores, they are detrimental to the ductility of forged Ti-5Al-2.5Fe parts. The elongation to fracture of the forged Ti-5Al-2.5Fe alloy is improved by subsequent heat treatments including solution and aging treatment and mill annealing, which convert the forged Ti-5Al-2.5Fe alloys a low cost good alternative to Ti-6Al-4V. Solution and aging treatment increase the tensile strength of forged Ti-5Al-2.5Fe parts significantly and can be used to tailor the properties of the alloy.

\section{Acknowledgments}

The financial support from New Zealand Ministry of Business, Innovation and Employment (MBIE) through the TiTeNZ (Titanium Technologies New Zealand) UOWX1402 research contract is sincerely acknowledged. 


\section{References}

[1] R. Boyer, An overview on the use of titanium in the aerospace industry, Materials Science and Engineering: A 213(1996), 103-114.

[2] F. Froes, H. Friedrich, J. Kiese, D. Bergoint, Titanium in the family automobile: the cost challenge, JOM Journal of the Minerals, Metals and Materials Society 56(2004), 40-44.

[3] I. Gurrappa, Characterization of titanium alloy Ti-6Al-4V for chemical, marine and industrial applications, Materials Characterization 51(2003), 131-139.

[4] M. Niinomi, Mechanical properties of biomedical titanium alloys, Materials Science and Engineering: A 243(1998), 231-236.

[5] M. Niinomi, Recent research and development in titanium alloys for biomedical applications and healthcare goods, Science and technology of advanced Materials 4(2003), 445.

[6] C. Elias, J. Lima, R. Valiev, M. Meyers, Biomedical applications of titanium and its alloys, Jom 60(2008), 46-49.

[7] S.L.d. Assis, I. Costa, Electrochemical evaluation of Ti-13Nb-13Zr, Ti-6Al-4V and Ti-6Al-7Nb alloys for biomedical application by long-term immersion tests, Materials and Corrosion 58(2007), 329-333.

[8] F. Pilehva, A. Zarei-Hanzaki, M. Ghambari, H. Abedi, Flow behavior modeling of a Ti-6Al-7Nb biomedical alloy during manufacturing at elevated temperatures, Materials \& Design 51(2013), 457-465.

[9] L. Bolzoni, T. Weissgaerber, B. Kieback, E.M. Ruiz-Navas, E. Gordo, Mechanical Behaviour of Pressed and Sintered CP Ti and Ti-6Al-7Nb Alloy Obtained from Master Alloy Addition Powder, Journal of the Mechanical Behavior of Biomedical Materials 20(2013), 149-161.

[10] R. Siqueira, H. Sandim, A. Hayama, V. Henriques, Microstructural evolution during sintering of the blended elemental Ti-5Al-2.5 Fe alloy, Journal of Alloys and Compounds 476(2009), 130-137.

[11] M.V. Popa, I. Demetrescu, E. Vasilescu, P. Drob, A.S. Lopez, J. Mirza-Rosca, C. Vasilescu, D. Ionita, Corrosion susceptibility of implant materials $\mathrm{Ti}-5 \mathrm{Al}-4 \mathrm{~V}$ and $\mathrm{Ti}-6 \mathrm{Al}-4 \mathrm{Fe}$ in artificial extra-cellular fluids, Electrochimica Acta 49(2004), 2113-2121.

[12] P. Esteban, L. Bolzoni, E.M. Ruiz-Navas, E. Gordo, PM processing and characterisation of Ti-7Fe low cost titanium alloys, Powder Metallurgy 54(2011), 242-252.

[13] Y. Liu, L. Chen, H. Tang, C.T. Liu, B. Liu, B. Huang, Design of powder metallurgy titanium alloys and composites, Materials Science and Engineering: A 418(2006), 25-35.

[14] C. Cui, B. Hu, L. Zhao, S. Liu, Titanium alloy production technology, market prospects and industry development, Materials \& Design 32(2011), 1684-1691.

[15] O.M. Ivasishin, V. Anokhin, A. Demidik, D.G. Savvakin, Cost-effective blended elemental powder metallurgy of titanium alloys for transportation application, Key Engineering Materials, Trans Tech Publ, 2000, pp. 55-62.

[16] T. Fujita, A. Ogawa, C. Ouchi, H. Tajima, Microstructure and properties of titanium alloy produced in the newly developed blended elemental powder metallurgy process, Materials Science and Engineering: A 213(1996), 148-153.

[17] G. Lütjering, Influence of processing on microstructure and mechanical properties of $(\alpha+\beta)$ titanium alloys, Materials Science and Engineering: A 243(1998), 32-45.

[18] G. Welsch, R. Boyer, E. Collings, Materials properties handbook: titanium alloys, ASM international1993.

[19] M.J. Donachie, Titanium: a technical guide, ASM international2000. 